sible for national health insurance consents to the adoption of the plans of the Research Committee they will be subjected to examination and criticism by the Advisory Council, which is a large and representative body including most of the members of the Departmental Committee. It was appointed by $\mathrm{Mr}$. Lloyd George after receiving suggestions for suitable names from each of the universities of the United Kingdom, from the Royal Colleges of Physicians and of Surgeons, from the Royal Society, and from other public bodies interested in the question. It includes medical representatives of the four National Health Insurance Commissions, and the other Government departments concerned in medical work.

\section{SIR JONATHAN HUTCHINSON, F.R.S.}

WHEN the history of modern medicine comes to be written it is certain that Sir Jonathan Hutchinson, who died in his eighty-fifth year at Haslemere on June 23 , will occupy a more prominent position than that usually assigned to him by his contemporaries. He had the misfortune to be at work when Pasteur and Lister opened up new, attractive, and practical fields of research, carrying with them all the eager intellects of a younger generation, and leaving the subject of this notice to explore the inexhaustible fields of clinical medicine. From the year 1844, when he was apprenticed to Dr. Caleb Williams, of York, at the age of sixteen, until the day of his death, within a month of finishing his eighty-fifth year, he never ceased to study the manifestations of health and disease, and to place his observations and inferences on record.

Sir Jonathan Hutchinson was an inductive philosopher who patiently and accurately collected facts to provide a sure basis for the principles of scientific medicine. The monument he leaves behind him is seen in the volumes of the "Archives of Surgery," "Atlas of Illustrations of Clinical Surgery," and the hundreds of clinical records which are to be found in medical literature of the last fifty years. He leaves behind him no brilliant discovery to fix his name in the public memory, and yet it may be claimed for him that he did more than any man of his time to solidify the foundations of the surgeon's art.

He was a self-made surgeon, neither the follower nor the leader of any school. It is true that after coming to London in $185^{\circ}$, at the age of twenty-two, he came under the influence of Lawrence and of Paget at St. Bartholomew's Hospital for a few months, but the spirit which dominated him when he ultimately settled in London was the quiet inquiring and observing mood which he acquired in the seclusion of his Quaker home in Selby. Before he was in his thirtieth year he was on the staff of the leading eye hospital (Moorfields), Blackfriars Hospital for Diseases of the Skin, the Metropolitan and the London Hospitals, where he had to deal with all the problems of general surgery.

With those great and varied clinical fields at NO. 2278 , vOL. 9I] his disposal he was able, in less than ten years from the time he settled in London, to produce convincing proof that a host of conditions which were regarded as separate diseases were really the remote manifestations of syphilis, and amenable to specific remedies.

The varied and puzzling diseases to which the skin was liable had a special attraction for Sir Jonathan Hutchinson, and it was at an early stage of his career that he began a systematic investigation of the cause and nature of leprosy. In 1859 he came to the conclusion that it was due to eating imperfectly preserved fish, and that the disease was therefore non-contagious and preventable. Fifty years later found him still searching in various parts of the earth for evidence to support his original contention.

The persistency which he applied to the study of leprosy he gave to all the various lines of research he took up. $\mathrm{He}$ was a student of growth; he never ceased recording facts and cases which were likely to reveal the principles which regulate the growth and development of the animal body. His lectures at the Royal College of Surgeons in I88r on the pedigree of disease are happy illustrations of the methods by which he sought to advance this kind of knowledge. He was a surgeon who made a reputation not by the use of the operating knife, but by the application of his intellect to the understanding and cure of disease. He operated with success; he introduced new procedures, but he recognised that recourse to operation was necessitated by the imperfections of the healer's art.

He was an educationist, believing that all teaching should be objective. He did much as chairman of the Museum Committee and as president of the College of Surgeons for the great museum founded by John Hunter; he established and furnished three museums in the Polyclinic (Medical Graduates' College) in Chenies Street, in his native town of Selby, and in Haslemere, where he latterly made his home.

\section{NOTES.}

We heartily congratulate Dr. A. F. R. Wollaston on his return from a successful visit to the Ingkipulu Mountains (Nassau range), Netherlands New Guinea. Last year Dr. Wollaston gave an account of the unlucky attempt of the British Ornithologists" Union Expedition in "Pygmies and Papuans," and quite recently Capt. C. G. Rawling has published another book on the same expedition, "The Land of the New Guinea Pygmies." On the present occasion Mr. C. B. Kloss, curator of the Kuala Lumpur Museum, accompanied Dr. Wollaston, and, in addition to an engineer and five native collectors, they took with them seventyfive "Dyaks," and a large escort was provided by the Netherlands Government. Four and a half months were occupied in reaching the mountains from the coast. The geographical results cannot be worked out for some time. Extensive zoological collections were made which comprise many new species; among 